\title{
EDUCATING PEERS ABOUT HUMAN SEXUALITY AND BIRTH CONTROL IN NATURAL SETTINGS: A SOCIAL COMPARISON PERSPECTIVE
}

ROCCO DE PIETRO, Ph.D.

Department of Health Behavior and Health Education, and Center for Population Planning, The University of Michigan, Ann Arbor, Michigan

\begin{abstract}
Adolescents are being trained to play several important roles in educating peers about human sexuality and birth control. A social comparison perspective offers numerous advantages over a persuasive communication perspective in the design, implementation, and evaluation of such peer-education programs. In the social comparison perspective, peer educators serve as social referents, providing standards of knowledge and behavior for the contacts with respect to understanding sexuality and preventing pregnancy.
\end{abstract}

\section{INTRODUCTION}

Programs that use adolescents to inform their peers about human sexuality and birth control are being introduced at a fairly rapid rate in a variety of natural settings. ${ }^{1,2}$ In these programs, adolescents are trained to play several roles: information provider, referral agent, and counselor are three of the most common ones.

The objectives of peer-education programs on human sexuality and birth control are informational as well as behavioral. While providing accurate information to make adolescents knowledgeable about these topics, they also attempt to modify adolescents' sexual and birth control behaviors to avoid pregnancy risk.

Peer-education programs on human sexuality and birth control are based in a variety of settings, such as clinics that provide contraceptive information and services to adolescents, community centers that have programs and services for youth, and schools that provide health-information programs for students, mainly those in high school.
This article addresses the question, "What are some reasonable expectations of peer education programs on human sexuality and birth control in natural settings?' I shall examine these programs from a social comparison perspective and generate a few informal hypotheses. Within this perspective, I question some of the common assumptions of these programs and raise some issues with respect to their design and implementation. I also propose a wider range of plausible intermediate effects and program outcomes than is suggested by the persuasive communication perspective, a widely used perspective in the field. These effects and outcomes should be of interest to health-care providers and educators responsible for the design, implementation, and evaluation of peer-education programs.

The notion of peer education is well-established in areas other than human sexuality and birth control. Self-help and mutual aid groups, ${ }^{3}$ for example, make use of peer educators. However, the use of peers in these contexts is quite different. First, peers in these groups are not trained to be experts on a specific topic. Their role is as much to provide affective support as it is to provide information. ${ }^{4}$ Second, peers in these groups communicate almost exclusively within the confines of a group context, whereas peer educators in human sexuality and birth control communicate mostly in dyads, although some of their work involves couples and small groups as well. Third, peers in these groups are involved largely in a two-way, equal exchange process, ${ }^{5}$ whereas the human sexuality and birth control peers are involved largely in a one-way, unequal exchange process. Fourth, groups in these settings often have a specific problem orientation, such as obesity, rheumatoid arthritis, or drug abuse..$^{6-8}$ Peer education on human sexuality and birth control has a much more diverse problem orientation, eg, choosing an appropriate method of birth control or answering a question someone was curious about. Fifth, whereas groups in these settings often come together to solve a common problem, the peer education dyad on human sexuality and birth control is formed with the idea that one member has the solution to the other's problem. Sixth, 
whereas peers in these settings are peers because they share a common problem, the peers of the peereducation dyad are peers because they share common social or demographic characteristics or, in some cases, common life experiences.

\section{ASSUMPTIONS OF PEER-EDUCATION PROGRAMS}

Peer-education programs tend to be based on three sets of assumptions: ones about the peer educators themselves, ones about their contacts, and ones about the expected outcomes of peer-educator-contact interactions. While these assumptions are usually unstated, they can be inferred from the way the programs are designed or implemented. .,10 $^{9}$

The assumptions about peer educators are that they:

1. Have social characteristics that are similar to or match those of their contacts

2. Are highly credible and trusted sources of information about human sexuality and birth control 3. Can be trained as information holders, or persons who provide accurate information to their contacts

4. Can play multiple roles

5. Can work equally effectively in a variety of settings while playing their multiple roles

Assumptions about persons contacted are that they:

1 . Will discuss openly with peer educators sensitive topics such as human sexuality and birth control

2. Will not be reluctant to contact a peer educator

3. Have interest in and need for information about human sexuality and birth control

4. Have similar and relatively constant and high levels of motivation for communication and learning

5. Have characteristics, such as their age and sex, that facilitate rather than inhibit communication with peer educators

Assumptions about the interaction process and its outcomes are that:

1. Mere exposure to a peer educator is sufficient to produce a sizable effect on the knowledge, attitudes, and behaviors of a contact.

2 . The interaction between peer educators and their contacts can best be described as a social influence or persuasive communication process.

3. Ultimate behavioral change, such as engaging in pregnancy risk reduction behaviors, is not only a reasonable expectation but also a likely outcome of this interaction process.

4. Contacts are likely to yield to the persuasive messages of peer educators because they are highly credible and trusted sources of information.
5. The processes by which this yielding occurs are less important than the programmatic outcomes themselves, such as engaging in pregnancy risk reduction behaviors.

Many of the foregoing assumptions are based, at least in part, on a persuasive communication perspective, which views the peer educators as active sources of information and their contacts as relatively passive recipients of information. ${ }^{11}$ The focus is not on the quality of interaction or mutual aid between peer educators and contacts but on the outcome of a largely one-way, persuasive communication process. Simple exposure to peer educators is assumed to produce sizable behavioral effects. The more exposure the greater the effect. The fact that peer educators can exert direct personal influence on the contacts only increases their potential impact. For the peer educators to be maximally effective, they have to be credible, trusted, and attractive sources of information. Their messages need to be well designed and tailored to the needs of persons they are attempting to reach. With these factors addressed, the persuasive communication approach suggests that direct effects on knowledge, attitudes, and behaviors are likely outcomes of the interpersonal communication process.

In fairness to peer-education programs that seem to operate from a persuasive communication perspective, some have broadened their view of persuasion. Some ask such questions as: What is the impact of the peereducation program on the peer educators themselves? As the result of participating in the program, have the peer educators become more credible sources of information? Have their values changed? Are they better able to discuss sexual and birth control issues with their parents? Recent theory and research suggest the importance of other effects, including a whole range of cognitive ones, such as the learning of counterarguments, improved information processing, and selfpersuasion. ${ }^{12,13}$

Viewing communication between peer educators and their contacts as largely a persuasive communication process has its limitations. First, it restricts the range of communication effects that one tends to examine as outcomes of the peer-education process. The perspective seems to have a strong bias toward predicting direct, as opposed to indirect, effects and behavioral change, as opposed to cognitive or communication changes. While direct behavioral change may be the outcome ultimately desired by program managers, the indirect or intermediate effects might be of considerable value in evaluating the overall effectiveness of a program. These intermediate effects might occur soon after an intervention, while the ultimate effects might be delayed for several months. Without the detection of these intermediate effects, programs might prematurely be judged failures that are actually in the process of succeeding. 
Peer-education programs are often designed to modify adolescents' sexual and birth control behaviors to reduce pregnancy risk or the occurrence of unwanted pregnancies. These outcomes can be viewed as ultimate programmatic effects or end products of a series of intermediate change processes resulting from contact with the peer educator. Conceptually, they can also be viewed as delayed effects, which are likely to occur only after a considerable passage of time. Meanwhile, the adolescent can engage in other important behaviors that will lead to the ultimate outcomes. We can view these interim behaviors as intermediate effects. They might include interpersonal and mass communication behaviors directed at new learning or decision making. Indirect effects, such as diffusion effects on peers, are also important. De Pietro ${ }^{14}$ demonstrated how peers of adolescents trained as holders of birth control information were stimulated by social comparisons to communicate and learn more about this topic.

The second limitation is that peer educators and their contacts tend to be treated as isolated dyads. This treatment fails to recognize that contacts are also members of other social units, such as families and social cliques, that could exert strong pressures on attitudes and behaviors. One extremely important relationship involves the boyfriend or girlfriend. A decision that a peer educator helps a contact to make could be quickly challenged by a boyfriend who is adversely affected by it.

Third, the social setting in which peer educators work can greatly facilitate or inhibit their informational and educational efforts. Some facilitators might include the stable presence of peer educator in the environment over time, opportunities for repeated contacts, easy accessibility, high visibility, and being a well known or liked personality. Some inhibitors might be the lack of institutional support for peer education, eg, a skeptical clinic director; norms about communication between members of different cliques, sexes, or age groups; concern over confidentiality, owing to the fact that people are in frequent contact with each other and each other's friends; the concern for privacy with respect to certain discussions; the requirement to budget time in accordance with schedules or routines; and the other roles that peer educators will be expected to play in various settings, such as, clique or organizational member. Natural settings have their own social systems with reward structures and status hierarchies. Peer educators are an integral part of these systems and must work within them to be effective in their programmatic roles.

Fourth, peer educators' performance on the job might be motivated by a number of things, such as the chance to exercise responsibility, engage in interesting work, influence others, or receive monetary compensation. The persuasive communication perspective places little emphasis on the source or level of motivation of peer educators or on the motivation of contacts. We know that contacts of peer educators often seek different types of information, such as information to help make a decision, to solve an immediate crisis, or to shed light on something they are curious about. However, we do not know much about the motives that cause them to initiate communication with a peer educator or the motives that develop as a result of these contacts. Motivation resulting from communication with peer educators would be especially helpful in understanding the outcomes of this interaction process. The persuasive communication perspective overlooks these sources of motivation as well.

Fifth, while peer educators have been found to play multiple roles on the job, ${ }^{1}$ the social comparison perspective suggests another vital role: that of psychological referent for knowledge and behavior. Considerable observational learning goes on in natural settings, and peer educators, because of their high visibility and accessibility, are readily available as comparison persons for sexual and birth control related topics.

\section{A SOCIAL COMPARISON PERSPECTIVE ON PEER EDUCATION}

Another perspective on the peer-education process is a social comparison perspective. ${ }^{14-17}$ This perspective has been used to help explain communication and learning about birth control as the result of exposure to information in mass media. ${ }^{14,18,19}$ It has also been used as a theoretical framework for examining other behavioral effects, such as self-rewarding behaviors ${ }^{20}$ and emergency helping behaviors. ${ }^{21,22}$ In school settings, it is being used to explain such outcomes as ability evaluations in mathematics and other subjects. ${ }^{23-25}$ Within this perspective, the relationships between peer educators and contacts become the focus of attention. Peer educators are used by contacts as social referents to estimate their abilities and behaviors with respect to sexuality and birth control. Contacts ask themselves such questions as: "How important is it for me to know about human sexuality and birth control?" "What attitudes about these topics is it appropriate for me to hold?" "What sexual and birth control behaviors is it appropriate for me to engage in?" Within this perspective, the peer educators help contacts answer these questions by establishing for them standards of comparisons for knowledge and behaviors.

Some of the most important premises of the social comparison perspective are:

1. Persons have an innate tendency to compare themselves with relevant others on a number of attributes, such as opinions, abilities, or behaviors, as a means of self-evaluation. The function of these self-evaluations is adaptation to the real world. 
2. In the absence of objective standards of appraisal, persons look to relevant others as referents for their opinions, abilities, and behavior. Usually, people select as referents relevant others or persons whom they perceive are similar to them. Such persons would include friends or age peers.

3. Persons compare themselves with relevant others on factors (opinions, abilities, behaviors) that are important to them.

4. Persons primarily evaluate abilities by comparisons upward; in the case of behaviors, they primarily evaluate them against some standard displayed or presented by peer educators.

5. When persons perceive discrepancies between their opinions, abilities, and behaviors and those of relevant others, they experience psychological discomfort. They attempt to avoid this discomfort by dealing with the perceived discrepancies. In doing so, they have several options. They could rationalize the discrepancies, ignore them, or adjust their attitudes to their referents. The latter case has the effect of making referents less relevant and thus rendering any perceived discrepancies between them less meaningful. But if the comparison factors and the referents are important, persons are likely to try to emulate the referents.

6. Communication behavior is a probable mechanism of discrepancy reduction, especially with respect to perceived discrepancies in abilities, eg, knowledge about specific topics.

7. Two factors affect the strength of social comparisons: the salience of a comparison person and the relevance of a comparison topic for actual behavior.

Having stated the premises of a social comparison perspective, we shall discuss its appropriateness for understanding peer-educator-contact communication about human sexuality and birth control.

\section{THE TENDENCY TO MAKE SOCIAL COMPARISONS}

\section{Contact with a Peer Educator and Social Comparison}

The first question we must address is whether contacts will make social comparisons about human sexuality and birth control knowledge and behavior with peer educators or other social referents. We believe that they will for the following reasons: Human sexuality and birth control knowledge and behaviors are salient topics for adolescents. Clarke and De Pietro ${ }^{19}$ found that, of the 410 adolescents between the ages of 13 and 17 whom they interviewed in a medium-sized industrial city, about $70 \%$ said that information about human sexuality and birth control was either very important or extremely important to them. Adolescents use own-age peers to estimate knowledge and behaviors that are important for adaptation to the peer environment. ${ }^{26}$ As own-age peers, peer educators provide such information through communication or overt behavior. In a sense, peer educators signal to other adolescents the importance of certain knowledge and the appropriateness of certain behaviors.

In the absence of objective standards, the adolescent needs assistance from relevant others, such as own-age peers, to make evaluations of relative knowledge and behaviors. One might argue that adolescents do not have to divulge to others their sexual and birth control knowledge or behaviors; therefore, any perceived discrepancies in them with own-age peers are unlikely to have severe social consequences, such as to embarrass persons who are less knowledgeable than their friends. While sexual and birth control knowledge might not be demonstrated in a social communication process the same way that knowledge of other topics might be, it still has relevance to some immediate or future behaviors. Sexual or birth control information is something that nearly everyone eventually has to acquire for successful adaptation to the real world.

\section{Selection of Comparison Persons}

It is likely that peer educators would be selected as comparison persons for sexual and birth control knowledge and behaviors. Many adolescents recognize that peer educators, having received special training on human sexuality and birth control, are "experts" on these topics. They also know that the institution has granted peer educators formal status as information providers within the setting. Peer educators can also have characteristics that increase their attractiveness as comparison persons and make them highly visible in the setting and readily accessible to contacts.

Contacts also make social comparisons with referents established for them in a communication process with peer educators. In their discussions with contacts, peer educators can establish two kinds of comparison persons: (1) generalized others, or psychological reference groups, such as "other couples" or "most other people your age"; and (2) specific referent others, or actual persons (without specifically mentioning names) whose knowledge or behaviors can be used to illustrate a point. An example of the former is an allusion to what "other couples" know or are doing about birth control. An example of the latter is an allusion to another adolescent who got pregnant because she avoided the use of contraception. Comparisons with referent others established by peer educators are likely to occur when peer educators and contacts are highly discrepant in a few impor- 
tant characteristics, such as sex, age, and social status within a setting.

\section{Selection of a Comparison Topic}

In general, the topics of comparison are likely to involve critical aspects of adolescents' sexual and birth control knowledge or behavior. Adolescents commonly cue each other as to what knowledge is highly valued or worth acquiring. Cliques sometimes form on the basis of knowledge or interest areas, such as cars or rock music. Some settings, such as schools, reward adolescents who acquire knowledge, thus increasing the likelihood that these comparisons will be made.

Behavioral comparisons are also important. In their attempt to learn about themselves and others, adolescents are keenly interested in the boundaries of acceptable behavior and are constantly testing parents, teachers, and friends in an attempt to determine these boundaries. Social comparison is a process that can help them make sense out of relevant behavioral cues from own-age peers. ${ }^{27}$

Behavioral comparisons about human sexuality and birth control are more difficult to make than are knowledge comparisons because the former are unlikely to be observed firsthand. While peer educators will openly discuss their sexuality and birth control knowledge with contacts, they are less willing to disclose their actual behavior in these areas. Apart from the fact that they regard their behavior as highly personal and confidential, some lack actual experience in these areas. Some female adolescents who serve as peer educators on human sexuality and birth control in clinic or school settings are concerned that their contacts assume that they are sexually active. ${ }^{28}$

Comparisons about behavior are more likely to be made with specific referent others or generalized others than with peer educators themselves. This might not be the case when a contact is a close personal friend of the peer educator, but it is likely to be true when the contact is not well known. In such cases, peer educators might wish to avoid disclosing sensitive information about their behavior for fear of rumors spreading about them. The problem of self-disclosure is likely to be greater for female peer educators because of the double standard regarding the sexual behavior of adolescent boys and girls.

Some psychological models of behavioral change suggest that people will modify their behavior if the perceived consequences for not doing so are psychologically intolerable. ${ }^{29,30}$ In the case of social comparisons about behavior with peer educators or psychological referents, people will reduce perceived discrepancies in behavior if the comparison person is important to them and the behavior itself has some relevance or immediacy to their own personal life.

\section{Relevance of Peer Educators as Comparison Persons}

The social comparison perspective suggests that adolescents are likely to select own-age peers as referents for human sexuality and birth control knowledge and behaviors. Peer educators are likely to be selected by contacts as referents for social comparison if they have similar social or demographic characteristics, such as sex, age, race, and status. Other characteristics might also be perceived, such as shared social experience, eg, living in the same community or having mutual friends. It is these perceived similarities that prompt contacts to make comparisons on topics in which large discrepancies are anticipated.

\section{Reducing Perceived Discrepancies in Knowledge and Behavior}

We expect that contacts will reduce perceived discrepancies by acquiring knowledge or attempting to make their behavior conform more to that of their comparison person. Failure to reduce these discrepancies leads to psychological discomfort that makes the contact feel uneasy or out of step with others. ${ }^{31}$ This psychological condition can be viewed as a form of peer pressure, which can provide a stimulus to new learning and behavioral change. ${ }^{14}$

In their role as counselors, peer educators are in a unique position to suggest ways of reducing discrepancies. For example, they can advise their contacts to catch up in knowledge or to engage in some behaviors that have helped them or others to prevent pregnancy. In a sense, they both establish the need to know or behave and find some ways for contacts to meet them.

An important mode of reducing perceived knowledge discrepancies is communication behavior. This communication can be purposive or goal directed, such as information seeking; or it can be nonpurposive, such as message discrimination or the casual noting and recalling of information on a specific topic in a medium during a recent time period. ${ }^{32}$ The principal mode of reducing perceived behavioral discrepancies is modifying behavior to conform better with one's comparison person. In modifying behavior, contacts keep in mind the behavioral standard set by the peer educator. It could be their own behavior or the behavior of an established referent or generalized other. To be effective as comparison topics, these behaviors have to be associated with a referent, either the peer educator or some psychological referents, such as "this person I talked to yesterday" or "most people our age."

Perceived discrepancies in knowledge about human sexuality and birth control create motivation to reduce these perceived discrepancies. Communication behavior directed at new learning is the mechanism of discrepancy reduction. Clarke and De Pietro ${ }^{19}$ found that some 
friends of adolescents trained in human sexuality and birth control attempted to reduce perceived discrepancies in knowledge by turning to the mass media for more information about these topics.

\section{FACTORS AFFECTING MOTIVATION FROM SOCIAL COMPARISONS}

The social comparison perspective suggests that two factors affect the strength of motivation resulting from social comparisons with referent others about knowledge and behavior: the salience of a comparison person and the relevance of comparison information (eg, the comparison topic) for immediate behavior.

\section{Salience of Comparison Person or Referent Other}

The importance of a psychological referent should affect the strength of motivation derived from social comparisons. Motivation should be strongest when comparisons are made with peer educators, followed by specific referent others and generalized others. These three referents differ in some important ways. Peer educators are actual referents, whereas the other two are psychological referents. They also differ with respect to their social distance from the contacts. Peer educators might be actual friends or acquaintances of contacts and, therefore, maintain a close social distance with contacts. Specific referent others and generalized others are unknown or abstract referents and, therefore, are more socially distant from contacts.

Motivation from social comparison should be strongest if there is a friendship tie, a strong liking or attraction, or a sense of "common fate."

\section{Relevance of Comparison Topic for Immediate Behavior}

Topics for comparisons involve human sexuality and birth control knowledge and behaviors. We distinguish between two forms of knowledge: (1) knowledge that is held in reserve for whatever reason and (2) knowledge that has potential for action.

From discussions with peer educators, we have found that contacts seek various kinds of information. Sometimes they just want general facts or information to satisfy their curiosity. In other instances, they might wish to know more about the work of the peer educators. We do not view these kinds of information as highly relevant to immediate sexual or birth control behaviors. More often than not, they are acquired with no fixed purpose in mind or as information to store for future use. However, some contacts approach peer educators with a problem, such as a dating problem or a pregnancy scare. They need information to help them cope with a crisis or to make a decision. In such instances, information has potential for action and is regarded as highly relevant to immediate behavior.

Behavioral comparisons about human sexuality and birth control have a stronger theoretical linkage to actual sexual and birth control behaviors than do knowledge comparisons. First, several behaviors can be engaged in to reduce perceived knowledge discrepancies, whereas a single behavior is the focus of perceived behavioral discrepancies. In a sense, the behavior that will be engaged in is preselected. Second, peer educators are often available to provide social support to contacts for their decisions about behavioral changes. Whether such support is actually provided, contacts are still able to perceive the availability of such support. Third, relying on others as referents for novel behaviors reduces the risks of engaging in these behaviors. There is the tendency to make comparisons about behaviors that seem at least to have positive consequences for others.

Not all behaviors that are topics of social comparison are likely to have the same effects on sexual and birth control behaviors. Behaviors differ in the extent to which they reduce pregnancy risk. Certain behaviors of peer educators or other referents that are compared might be only indirectly related to sexual and birth control behaviors, such as some planning and decisionmaking activities. Other behaviors, such as changing sexual behavior or using birth control pills properly, can have direct effects on the reduction of pregnancy risk.

\section{ADOPTING A SOCIAL COMPARISON PERSPECTIVE: SOME ISSUES}

There are some theoretical and methodological considerations in employing a social comparison model to develop peer-education programs on human sexuality and birth control. First, the perspective cannot be used to help understand many factors affecting the sexual and birth control behaviors of adolescents. Chilman, ${ }^{33}$ in a comprehensive review of research in these areas, has identified numerous background and psychological factors that impinge on these behaviors.

Adolescents also engage in numerous other psychological processes that affect their behaviors in these areas, such as generating their own estimates of the costs and benefits of contraceptive risk-taking ${ }^{34}$ or developing health beliefs about their susceptibility to serious consequences for engaging or not engaging in particular behaviors, coupled with beliefs about ways to reduce the likelihood of these consequences occurring at a psychological cost that is tolerable. ${ }^{29}$ The social comparison perspective places its emphasis on the generation of positive peer pressure to help bring about desirable behaviors. Other approaches, such as those suggested by Luker ${ }^{34}$ and Rosenstock, ${ }^{29}$ rely on an assumption that people are highly active in generating reasons 
for their behavior. In their view, peer pressure from social comparisons might be simply one of the costs to consider in deciding about behavior.

A somewhat different but related issue is whether motivation from social comparison or personal need provides the better framework for understanding adolescents' knowledge and behaviors. According to McGuire, ${ }^{35}$ the social comparison perspective depicts the individual as passive in regard to the initiation of human striving and external in regard to the origin of goal orientation of motives. As we noted, other perspectives consider them as much more internally motivated. We argue that a social comparison perspective is a reasonable one to adopt, given the importance of peer groups as reference groups for knowledge and behavior, ${ }^{26}$ and as agents of socialization. ${ }^{36}$ Also, some settings are structured to increase the likelihood that such comparisons occur, eg, schools where withinclassroom groupings are made on the basis of ability. ${ }^{23}$ Similarly, in some clinics a session with a peer educator is a routine part of many client visits.

We have been assuming that ability evaluations are upward, ie, that persons compare their relative abilities with someone who possesses more of some attribute. Hackmiller $^{37}$ reminds us that persons sometimes make downward evaluations. He investigated the role of ego defense mechanisms and found that the selection of comparison persons worse off than oneself can lead to self-enhancement, especially when persons feel threatened by the object or topic of orientation. It is possible that some evaluations about sexual or birth control behaviors could fall within this category. Persons with low self-esteem might fall into the trap of selecting as referents persons who do not adequately practice contraception.

In sum, taking a social comparison perspective on peer education about human sexuality and birth control in natural settings has certain advantages over the most widely used perspective. Its value lies in understanding motivation for communication behavior and other important outcomes. It also suggests some of the conditions under which these programs are likely to succeed or fail. Health-care providers or health educators in a variety of settings might profit from experimentation and use of this perspective. It offers them several options in the design, implementation, and evaluation of their programs.

\section{APPLYING A SOCIAL COMPARISON APPROACH IN A CLINIC SETTING}

In applying a social comparison approach in a clinic setting, there are several points to consider:

1. Recognize that a prominent role that the peer educator can play is that of psychological referent for knowledge and behavior.
2. Through selection processes, make sure that the peer educators match the social and demographic characteristics of their contacts. In this regard, it helps to use peer educators who have actually used birth control successfully so that they can speak authoritatively about their personal experiences. There is a definite advantage in hiring peer educators who are not embarrassed to talk about their personal experience with contacts or patients.

3. Encourage peer educators to establish psychological referents for knowledge and behavior by telling stories of successful contacts or patients who had problems similar to their own. While protecting the confidentiality of contacts or patients, peer educators could pool their collective knowledge of contraception users. These stories are remembered more than is factual information about birth control. The protagonists of the stories become the comparison persons for knowledge or behavior.

4. Test to see that social comparisons are made. For example, after telling a story, a peer educator could ask, "Does that sound like you?" Or if the peer educator was discussing some personal experience, he or she might conclude with the statement, "It seems like we were both in the same boat." In the case of low self-esteem contacts, make sure that comparisons about knowledge and behavior are being made with appropriate referents. It is important to guard against downward comparisons.

5. Help contacts reduce perceived knowledge or behavioral discrepancies by establishing some methods of discrepancy reduction. In the case of knowledge discrepancies, suggest some communication behaviors they might engage in such as talking to a boyfriend or girlfriend or reading a pamphlet that addresses their special area of concern. You might suggest that they attend a rap session on birth control at the clinic, if it is likely that they would profit from this form of social process. In the case of behavior, specify the activities that need to be accomplished. Help them anticipate some of the difficulties that they might encounter if they choose to engage in a particular behavior, such as the adoption of a birth control method. Help them to clarify how birth control fits into their personal lives. Even at this stage, social comparison processes can help contacts or patients to understand how birth control fits into the lives of peer educators or others like them. These comparisons can be powerful motivators of new learning and behavioral change. 


\section{REFERENCES}

1. Talbot JM, Rohrbach L, Coan CE, Kar SB. The status of teen peer advocate programs in the U.S. Unpublished report. Los Angeles, Califomia: School of Public Health, University of Califomia at Los Angeles, 1982.

2. Kar SB, et al. Impact of peer counseling on teen contraception in Los Angeles. Unpublished report. Los Angeles, California: School of Public Health, University of California at Los Angeles, 1981.

3. Katz A, Bender E. The strength in us: Self-help groups in the modern world. New York: Franklin Watts, Inc, 1976.

4. Israel B. Social networks and health status: Linking theory, research, and practice. Patient Couns Health Educ 1983; 4(2):6579.

5. Katz AH. Self-help and mutual aid: An emerging social movement? Annu Rev Sociol 1981; 7:129-155.

6. Sevitz LS, Stunkard A. A therapeutic coalition for obesity: Behavior modification and patient self-help. Am J Psychiatry $1974 ; 131(4): 423-427$

7. Potts $\mathrm{M}$, Brandt KD. Analysis of education-support groups for patients with rheumatoid arthritis. Patient Couns Health Educ $1983 ; 4(3): 161-166$.

8. Volkman R, Cressey D. Differential association and the rehabilitation of drug addicts. Am J Sociol 1963; 69:129-142.

9. Directory of Teen Peer Advocate Programs. Unpublished report Los Angeles, California: Los Angeles Family Planning Council, Inc., March 1982.

10. The peer education program. Brochure. Ann Arbor, Michigan: Washtenaw County League for Planned Parenthood, 1983

11. Fisher BA. Perspectives on human communications. New York: Macmillan Publishing Co, 1978

12. Petty RE, Ostrom TM, Brock TC, eds. Cognitive response in persuasion. Hillsdale, New Jersey: Lawrence Erlbaum Associates, Inc, 1981

13. Roloff M, Miller GR, eds. Persuasion: New directions in theory and research. Beverly Hills, Califomia: Sage Publications, Inc, 1980.

14. DePietro RA. Can adolescents be motivated to learn about birth control? Int $Q$ Commun Health Educ 1982-83; 3(4):337-350.

15. Festinger L. A theory of social comparison processes. Hum Rel $1954 ; 7: 117-140$.

16. Latane B, ed. J Exp Soc Psychol 1966 (Suppl 1):1-5.

17. Suls JM. Miller RL. Social comparison processes. New York Hemisphere Publishing Corp, 1977.

18. Kline FG, Miller PV, Morrison AJ. Adolescents and family planning information: An exploration of audience needs and media effects. In: Blumler JG, Katz E, eds. The uses of mass communication. Beverly Hills: Sage Publications, Inc, 1974:113-136.

19. Clarke P, DePietro RA. Delivering information on human sexuality and birth control to teenagers: The test of a social comparison approach. Report submitted to the Charles Stewart Mott Foundation, Flint, Michigan, 1980.

20. Masters JC. Social comparison by young children. In: Hartup W, Smothergill NL, eds. The young child. Vol 1. Washington, D.C.: National Association for the Education of Young Children, 1972.

21. Beaman $A L$. The effects of evaluation apprehension and social comparison on emergency helping behavior, Diss Abs Int 1973; 3:6056.

22. McNeel SP, Sweeny JD, Bohlin PC. Cooperation and competitive goals: A social comparison analysis. Psychol Rep 1974; 24:887-994.

23. Reuman DA, et al. Social comparison on ability evaluations in mathematics. Paper presented at the 91st annual convention of the American Psychological Association, Anahcim, California, August, 1983

24. Eccles J, et al. Expectancies, values, and academic behaviors. In: Spence JT, ed. Achievement and achievement motives. San Francisco: WH Freeman and Co, 1983.

25. Levine JM. Social comparison and education. In: Levine JM, Wang MC, eds. Teacher and student perceptions: Implications for learning. Hillsdale, New Jersey: Lawrence Erlbaum, Associates, Inc, 1983.

26. Kemper TD. Reference groups, socialization and achievement In: Borgatta EF, ed. Social psychology: Readings and perspective. Chicago: Rand McNally and Co, 1968.

27. Jones EE, Gerard HB. Foundations of social psychology. New York: John Wiley and Sons, 1967.

28. Personal communication with a peer educator of the Washtenaw County League for Planned Parenthood, Ann Arbor, Michigan, September 1983.

29. Rosenstock IM. The health belief model and nutrition education. $J$ Can Dietet Assoc 1982; 3:184-192.

30. Rosenstock IM. The health belief model and preventive health behavior. Health Educ Monogr 1974; 2:354-386.

31. Newcomb TM. An approach to the study of communicative acts. Psychol Rev 1953; 60:393-404.

32. Clarke P, Kline FG. Media effects reconsidered. Commun Res $1974 ; 1: 224-240$.

33. Chilman C. Adolescent sexuality in a changing American society. Washington, D.C.: U.S. Government Printing Office, 1980.

34. Luker K. Taking chances: Abortion and the decision not to contracept. Berkeley: University of Califomia, 1975.

35. McGuire WJ. Psychological motives and communication gratification. In: Blumler JG, Katz $\mathrm{E}$, eds. The uses of mass communications. Beverly Hills: Sage Publications, Inc, 1974:167-196.

36. Coleman JS. The adolescent society. New York: Free Press, 1961

37. Hackmiller KL. Need for self-evaluation, perceived similarity and comparison choice. J Exp Soc Psychol 1966 (Supplement $1): 49-54$. 